\title{
Juvenile systemic lupus erythematous in Iranian children
}

\author{
Fatemeh Tahghighi", Vahid Ziaee, Mohamad-Hassan Moradinejad, Fatemeh Fereshteh Mehregan \\ From 21st European Pediatric Rheumatology (PReS) Congress \\ Belgrade, Serbia. 17-21 September 2014
}

\section{Objectives}

Juvenile systemic lupus erythematous (JSLE) is a multisystem autoimmune disorder of unknown origin. Involvement of the mucocutaneous, musculoskeletal system and kidney disease are the most common manifestation of JSLE. This investigation was performed to define the demography and clinical manifestation of JSLE in Iran.

\section{Methods}

Fifty nine patients with JSLE were enrolled in this retrospective study. All patients fulfilled the American College of Rheumatology revised criteria 1982 for the diagnosis of SLE and had shown clinical manifestations of the disease before the age of 16 .

\section{Results}

A total of 59 patients, 49 (89\%) were female and10 (16.9\%) male. The female to male ratio was 4.9:1. The mean age of onset was 10.5 years (range $2-16$ ). The mean duration of disease from diagnosis was 2 years (range7 months-5 years). The most common of constitutional sign was fatigue (76.3\%) and the other signs were fever (32.2\%), Nocturnal pain (20.3\%), Mood disorder (20.03\%), and Weight loss (22\%). The most common manifestation of JSLE were as follows: 48 patients (81.35\%) had mucocutaneous involvement, 46 patients (77.9\%) had musculoskeletal involvement, 25 children (42.37\%) suffered from renal disease, hematological abnormalities were detected in 19 patients (32.2\%), 10 patients $(16.94 \%)$ had cardiovascular disease, 33 patients (55.93\%) presented nervous system involvement, 12 patients $(20.33 \%)$ had pulmonary disease, and 13 patients (22.03) experienced infection complications. During the follow up period(3years) two patients died, one from renal failure, one from infections.

\footnotetext{
Division of pediatric Rheumatology, Children's Medical Center, Tehran
} University of Medical Sciences, Tehran, Iran, Islamic Republic Of

\section{Conclusion}

A high index of suspicion must be preserved for the diagnosis of SLE in adolescent children, particularly girls. Juvenile systemic lupus erythematous (JSLE) is a critical multi-system organ disease. JSLE still has a significant mortality rate high, although it has a high remission rate with early diagnosis and treatment.

\section{Disclosure of interest}

None declared.

Published: 17 September 2014

doi:10.1186/1546-0096-12-S1-P330

Cite this article as: Tahghighi et al:. Juvenile systemic lupus erythematous in Iranian children. Pediatric Rheumatology 2014 12(Suppl 1):P330.
Submit your next manuscript to BioMed Central and take full advantage of:

- Convenient online submission

- Thorough peer review

- No space constraints or color figure charges

- Immediate publication on acceptance

- Inclusion in PubMed, CAS, Scopus and Google Scholar

- Research which is freely available for redistribution
() Biomed Central 